\title{
Rehabilitation and restoration of flood-damaged lowlands - an example in the Tokyo Lowlands
}

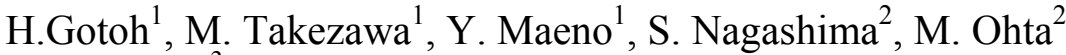 \\ \& H. Oshiki ${ }^{3}$ \\ ${ }^{1}$ Department of Civil Engineering, College of Science and Technology, \\ Nihon University, Japan \\ ${ }^{2}$ Tokyo Metropolitan Government, Japan \\ ${ }^{3}$ Japan Institute of Construction Engineering, Japan
}

\begin{abstract}
Several large rivers are concentrated in the lowlands of eastern Tokyo. The area through which the Sumida River, the Ara River, the Naka River, and the Edo River flow has benefited considerably from the opportunities provided by the waterways, but the area has been impacted repeatedly by floods and high tides. The lowlands of eastern Tokyo have been flooded numerous times. Built in response to historic flooding in the Tokyo lowlands, flood control measures such as channels, dikes and gates have mitigated the impacts of exceptionally high tides.

Japan is a country frequently affected by earthquakes. Many houses and people in Tokyo were lost during the major earthquakes of 1703, 1855 and 1923. A major earthquake in the Tokyo lowlands, which lies below sea level, could potentially destroy dikes, subways, lifelines such as electricity and gas, and information networks, affecting the entire country. Therefore, measures to reinforce dikes during earthquakes have been developed. The preparedness and education of residents living in flood-prone areas along the rivers are necessary to reduce concerns in emergency situations. In addition, river facilities such as dikes and gates must be maintained by river managers, and river environments and wetlands must be restored.

Keyword: flooding, high tide, lowlands, attitude surveys.
\end{abstract}




\section{Introduction}

The Tokyo metropolitan area is the center of government and commerce in Japan. The commercial area, which is concentrated in the eastern parts of Tokyo, contains a high density of both residential and commercial properties. The eastern parts of Tokyo have been inundated by numerous floods because of the many rivers that flow through this area, i.e., the Sumida River, the Ara River, the Naka River, and the Edo River, as mapped in Figure 1. In addition, the ground level in certain parts of eastern Tokyo is below sea level and below the river surface. Figure 1 shows a map of the area with the highest potential for flood tide impacts. Approximately three million people live in the dangerous area where the ground level is currently $1.0 \mathrm{~m}$ below sea level.

In the present paper, we outline the potential for flooding in the Tokyo lowlands and examine the progress of river improvement projects such as flood control channels, dikes, and gates in the Tokyo lowlands. In addition, the success of long-term rehabilitation and restoration work in flood-damaged areas is investigated. Moreover, we conducted a survey of the residents living in the eastern Tokyo lowlands to identify attitudes toward flood hazards and flood control measures.

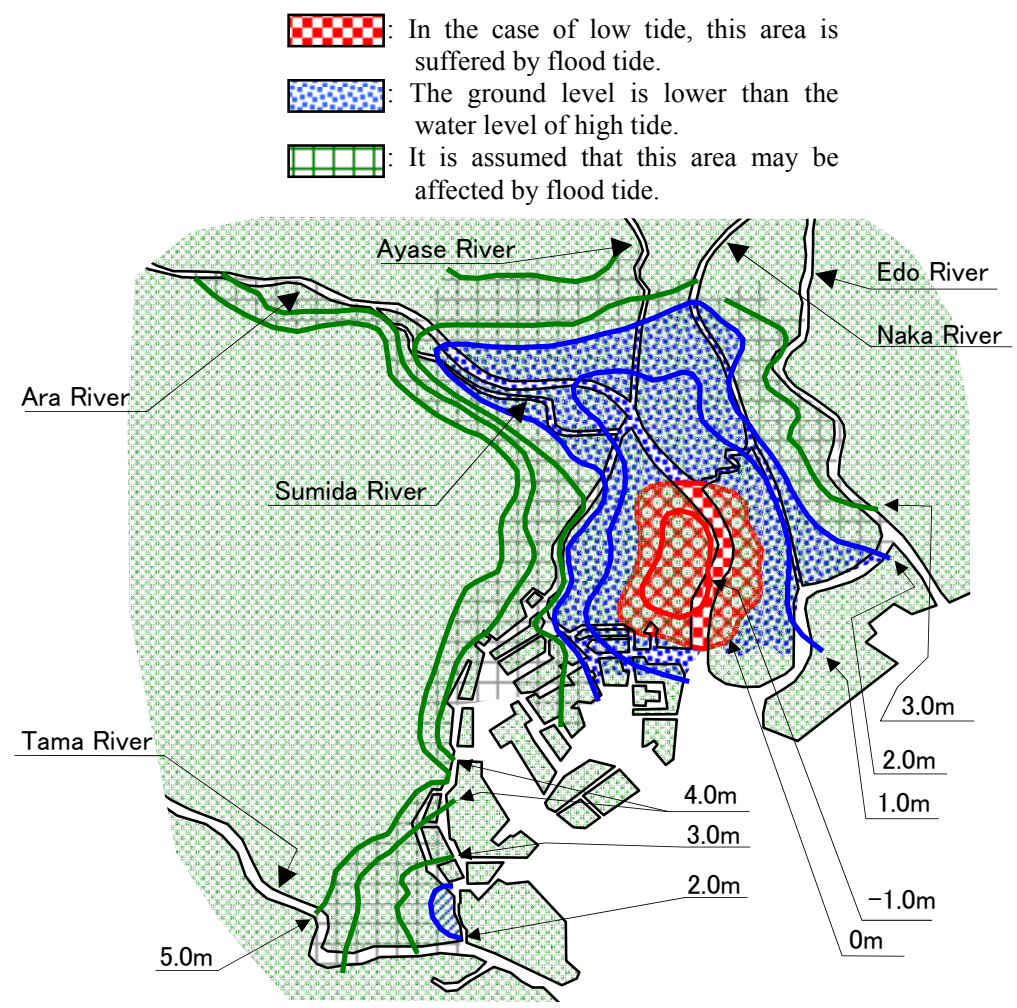

Figure 1: Description of the Tokyo lowlands. 


\section{Shifts in the Tokyo lowlands}

Historically, wetland areas existed in the Tokyo lowlands, located at the mouths of the larger rivers, such as the Tone River and the Ara River (Figure 2(a)) [1]. In the Edo Era (1603-1867), the wetland was reclaimed through river improvement works ordered by the Tokugawa Shogunate to promote shipping and control flood dangers. In the Meiji Era (1868-1912), the drainage canals were constructed for flood control in the Ara River and the Naka River. As a result, the eastern part of Tokyo was built up as shown in Figure 2(b).

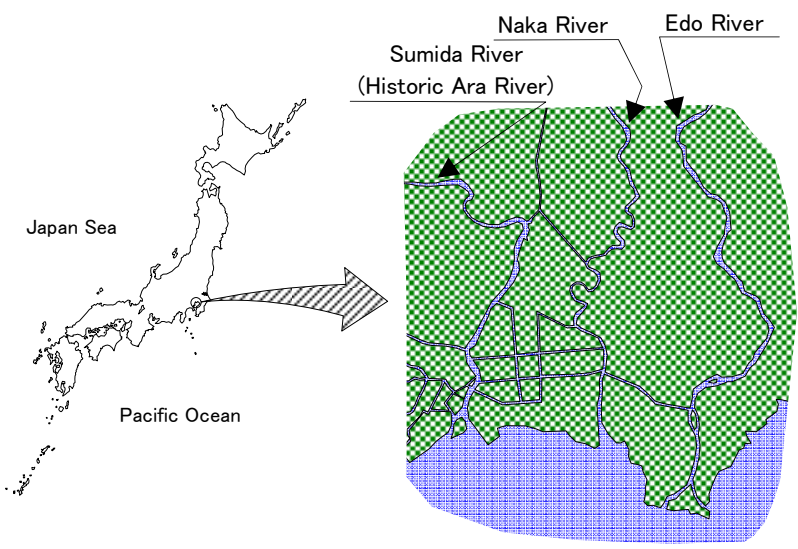

(a) Topography in the Meiji Era (1897)

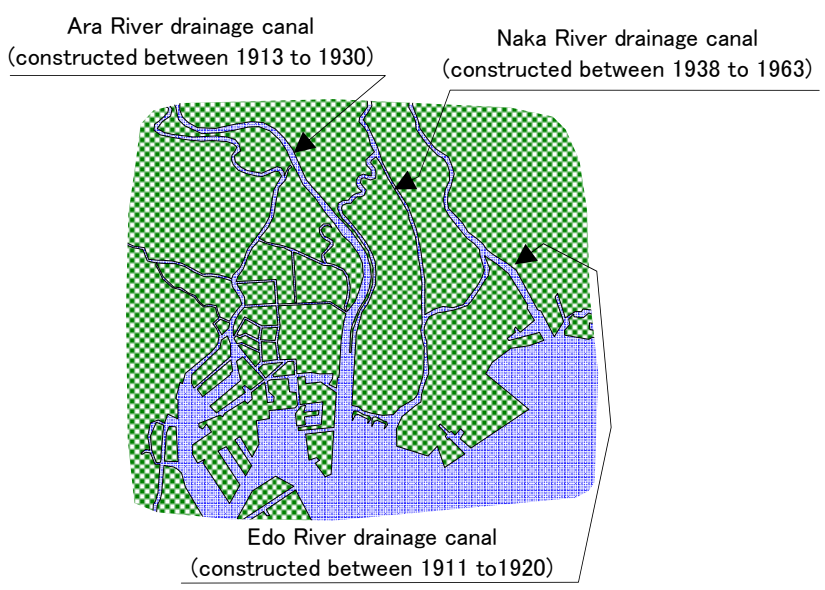

(b) Topography in the present day (2007)

Figure 2: Changes to the Tokyo lowlands. 
From the end of the Meiji Era to the 1970's, land subsidence occurred because of ground water withdrawal in the Tokyo lowlands. To prevent the land subsidence, laws restricting the utilization of industrial water and a regulation limiting ground water withdrawal (the Industrial Water Law (1963) and the Law of Ground water Utilization in Buildings (1965)) were enacted. As a result, land subsidence in the Tokyo lowlands ceased during the 1980's, but the ground level remained below sea level and lowland residents were still vulnerable to flood hazards.

\section{History of flooding in the Tokyo lowlands}

Several large rivers, such as the Sumida River, the Ara River, the Naka River, and the Edo River, flow through the eastern part of the Tokyo metropolitan area. Although the residents in this area have had the advantages of transportation by water, frequent floods and high tides have ravaged the area. Recent major flooding events in the Tokyo lowlands are described below $[2,3]$.

\subsection{Typhoon Kathleen}

Typhoon Kathleen hit the Kanto district in September 1947, with exceptionally heavy rainfall. Dikes along the Tone and Ara Rivers collapsed from the heavy rain and floodwaters flowed into the Tokyo lowlands. The government of the metropolis of Tokyo undertook measures to flush out floodwaters to prevent water from inundating the Tokyo lowlands. The preventative measures included the decision by the governor of Tokyo to blow up the dikes along the Edo River to remove barriers and flood flow into the Edo River. However, the mitigation attempts were not successful and floodwaters flowed into the Tokyo Bay and throughout the Tokyo lowlands. As a result, approximately 3500 casualties were existed, and 400,000 houses were inundated. In the aftermath of the flooding, dams were constructed in the upper reaches of the Tone and Ara Rivers to prevent future flood damage.

\subsection{Typhoon Kitty}

On August 31, 1949 Typhoon Kitty hit the Kanto district, coming ashore in Kanagawa prefecture on the south side of the Tokyo lowlands. The central pressure was $956 \mathrm{hPa}$ and heavy precipitation occurred in the north area of the Kanto district. The storm surge flowed onshore, scouring the earthen dikes. As a result, the weakened dikes along the Ara and Naka River broke under the floodwaters, inundating the Tokyo lowlands area as shown in Figure 3. During Typhoon Kitty, 639 casualties were existed, and approximately 161,000 houses were destroyed or inundated by flooding.

\subsection{Typhoon Kanogawa}

Typhoon Kanogawa hit the Tokyo area on September 21, 1958. The central pressure was $877 \mathrm{hPa}$. Typhoon Kanogawa caused heavy rain in the Kanto district 
and peak rainfall in the Tokyo area reached $392.5 \mathrm{~mm} / \mathrm{day}$. As a result, approximately 526,000 homes were destroyed or inundated, and approximately 2400 casualties were existed.

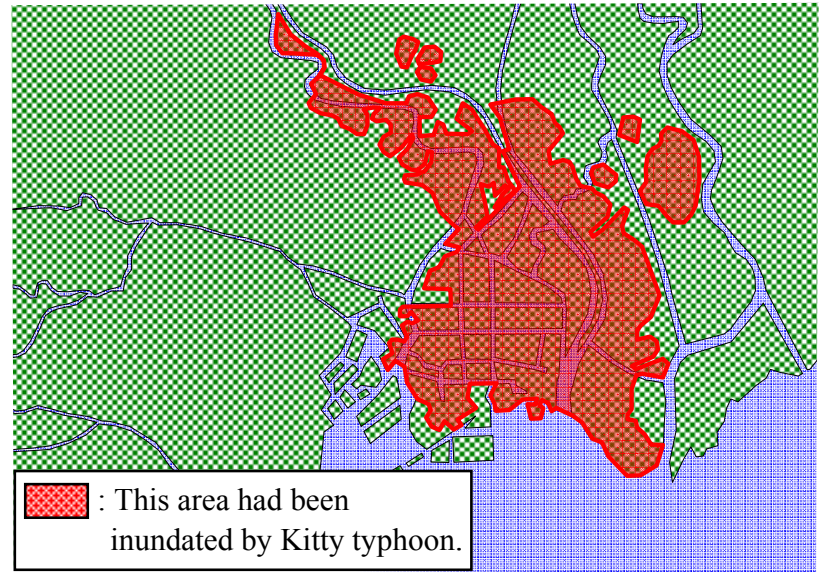

Figure 3: Area flooded by Typhoon Kitty.

\section{Rehabilitation of flood damage and restoration of the lowland}

To protect the Tokyo lowlands from flood hazards, drainage canals were constructed on the Ara and Naka Rivers and existing dikes and gates were maintained [1]. In addition, flood time measurements were taken in the Tokyo lowlands.

After Typhoon Kitty, the first flood control project began in 1949. The Tokyo metropolitan government appropriated 2,000,000,000 yen for flood disaster recovery measures and constructed dikes totaling $108 \mathrm{~km}$ and 38 flood gates from 1949 to 1956 . In the following decade, land subsidence occurred because of the utilization of water for industrial purposes as the Japanese economy grew. In addition, the condition of existing flood control facilities deteriorated and in 1957, a second flood tide control project was started, which was designed to a higher tide level.

Typhoon Isewan struck Nagoya City in 1959. The highest storm surge ever recorded in Japan destroyed existing flood control structures near Nagoya City. After the Typhoon Isewan disaster, dikes, seawalls, gates, and drainage facilities constructed in the Tokyo Bay area were designed to withstand typhoon conditions of similar intensity. However, the tall dikes and the seawalls that were constructed (shown in Figure 4(a) and Figure 5) separated the residential areas from the river and coastal areas. As a result of the limited access, residents lost interest in the river and the coastal areas.

In 1963, plans for river improvement projects were initiated, focusing on the Sumida River, the Naka River, Edo River, the Shinnaka River, and the Ayase River within the core of the Tokyo lowlands. The goal of the river improvements 
was to improve access to the water while strengthening dikes against earthquake damage. Existing dikes were reconstructed to create "dikes with mild slopes" beginning in 1980 (Figure 4(b)), and subsequently the construction of the "super-dike project" further improved residential safety in the event of flooding or earthquakes. The super-dike project was designed as pictured in Figure 4(c). For example, the Ministry of Land, Infrastructure and Transport has defined the super dike as follows; (1) The width of the dike is approximately 30 times the height, and buildings and roads were constructed on artificial ground fill. (2) The super-dike is stronger than the old dikes in the event of floods and earthquakes.

By 2005, 92\% of the dikes in the Tokyo lowlands area shown in Figure 6 were reconstructed to the specifications of the super-dike projects.

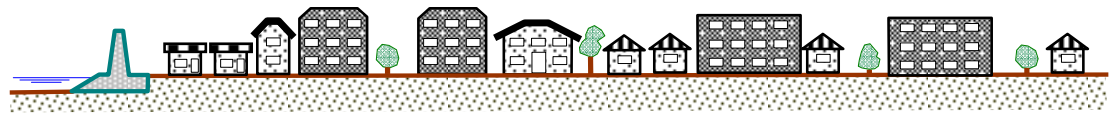

(a) Old dikes

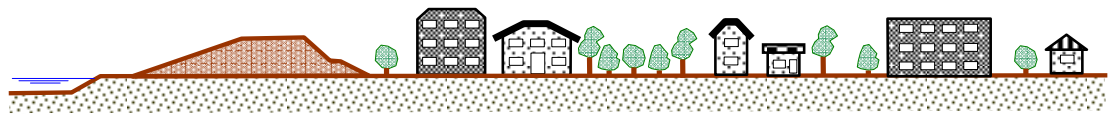

(b) Dikes with mild slopes

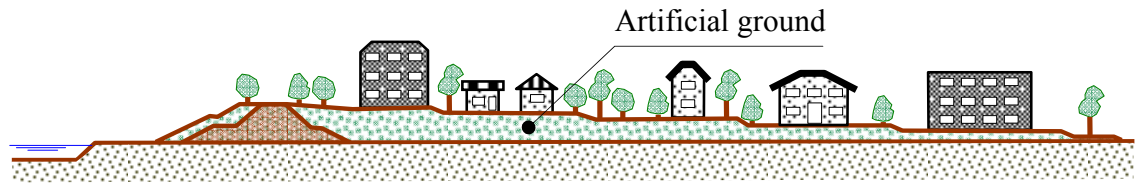

(c) Super dikes

Figure 4: Schematic representation of dikes.

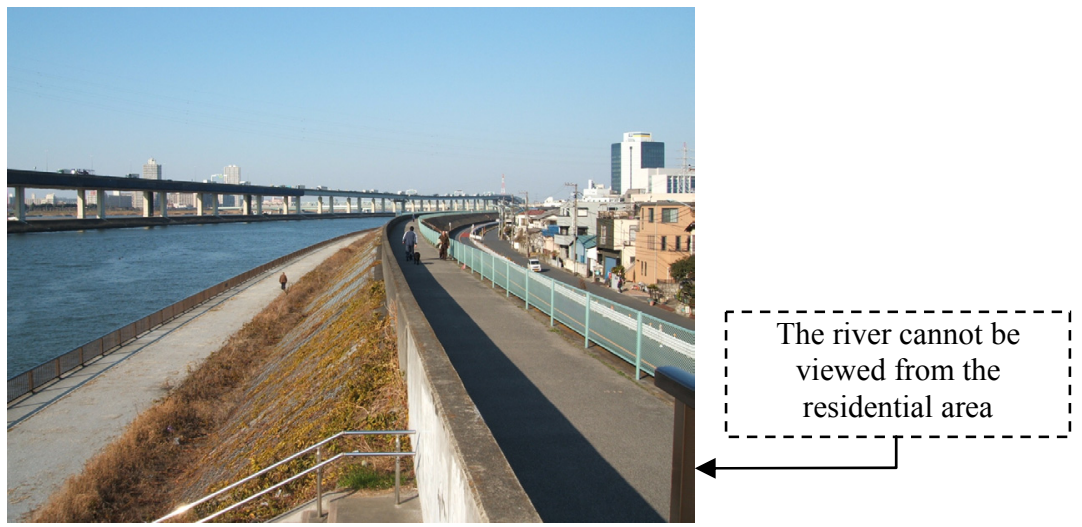

Figure 5: Photograph of a residence along the old dikes (On the Naka River in the Kasai area). 


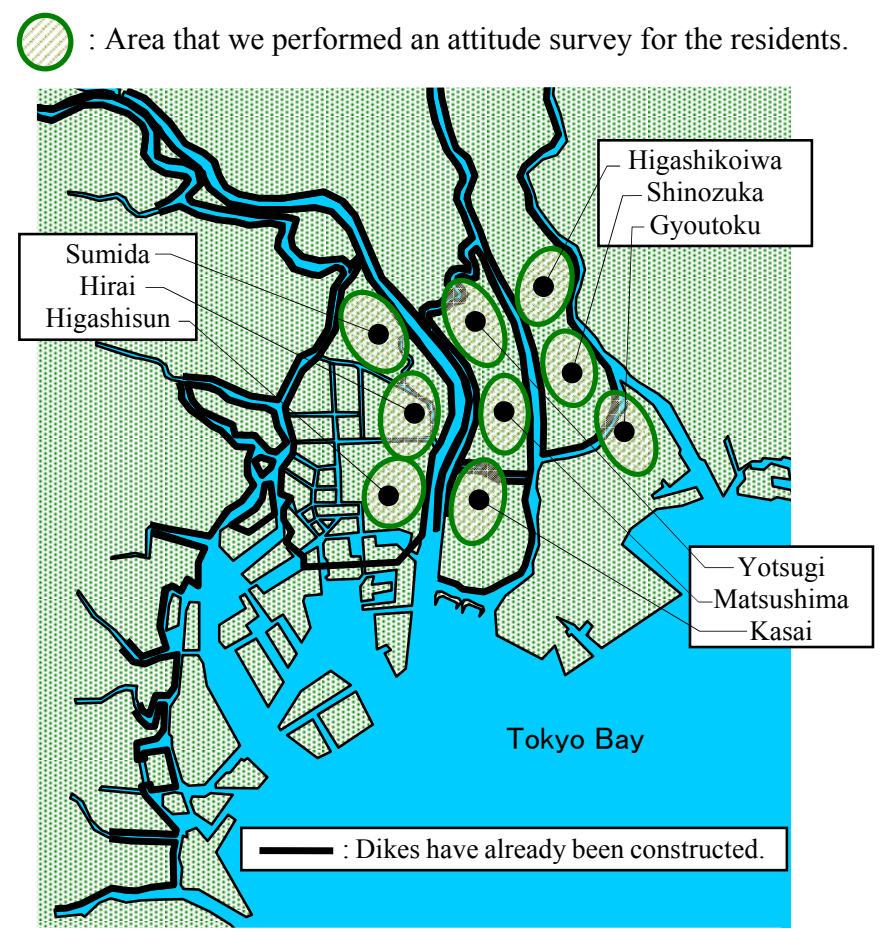

Figure 6: Execution of dike construction.

\section{Attitudes of residents in the Tokyo lowlands}

To evaluate the attitudes of residents toward flood control measures, a questionnaire was distributed to 4500 residents living within the 9 areas along the Ara and Edo Rivers shown in Figure 6 [4]. The content of the survey is shown in Table 1 . The questionnaires were delivered only to detached houses; residents living in apartment houses were not targeted in the present study. An average response rate of $21.5 \%$ was achieved among residents in the different areas. Unfortunately, the distribution of questionnaires to the owners of detached houses restricted the pool of respondents to primarily elderly residents. Male and female respondents provided similar answers to each question.

Figure 7 shows radar charts of the marginal count in this survey. As shown in Figure 8, the differences among residents of the Ara River drainage basin and the Edo River basin can be clearly distinguished. The trends in the responses to Qs.6, $8,9,13$, and 15 differ markedly. From responses to Q.6, 8, and 13, the residents living along the Edo River indicated that the strength of the levee is sufficient and that flooding is not a concern, in contrast to the attitude of residents living along the Ara River. In the event of a flood, Edo River residents believed they could evacuate safely and easily. The responses to Q.9 show that the differences in the 
attitudes of residents are attributable to previous flooding experience. A large percentage of the residents were not afraid of flood hazards, as can be seen in responses to Q5 in Figure 7.

Table 1: Content of the questionnaire supplied to residents.

Please answer the questions below:

1. Sex? (Male or Female?) 2. Age? 3. Job? 4. Address?

5. Are you in danger of flooding from the River? (Yes or No)

6. Is the levee height a source of worry for you? (Yes or No)

7. Have you walked on the levee? (Yes or No)

8. Do you think that the height and the width of the levee are sufficient? (Yes or No)

9. Has your property ever been damaged by flood? (Yes or No)

10. Are you in danger of tidal waves (Tsunami)? (Yes or No)

11. Do you think that the levee is sufficiently strong should an earthquake occur? (Yes or No)

12. In case of flooding, do you know where your designated evacuation area is? (Yes or No)

13. Do you think the evacuation area is safe? (Yes or No)

14. Is the evacuation area far from your place of residence? (Yes or No)

15. Do you think your residential area has a good environment? (Yes or No)

16. Do you think there are enough convenient facilities (train station, shops, and so on) for living in your residential area? (Yes or No)

\section{Future projects in the Tokyo lowlands}

Historically, the rivers flowing through the Tokyo lowlands played a vital role in the development of the Tokyo metropolitan area because of the importance of to shipping and transportation, and the significance of the rivers in the life of lowland area residents. However, after the Meiji Era, the residents lost their affinity for the rivers because of floods, water pollution, and land subsidence. To reinstate the value of the rivers, the river environments should be restored by evaluating the area history and the properties along the rivers. The river restoration measures are discussed below.

\subsection{Philosophy of river improvement projects: an example of eastern part of Tokyo "Koutou area"}

The restoration of river environments has been undertaken based on six aims outlined by the Tokyo metropolitan government in $1999[5,6]$. The six aims are: (1) to increase the affinity of residents for the rivers; (2) to construct a beautiful landscape, which includes a view of the river and clean river water; (3) to increase the use of riverfront areas by residents for communicating with neighbors and as a location for community events; (4) to cultivate aquatic life and aquatic plants in the rivers so as to reinstate the citizens' connection with nature and to provide a place for education about the natural world; (5) by cooperating with factories and stores at riversides; and, (6) to use the rivers for fire fighting and recovery efforts in the event of earthquakes. 

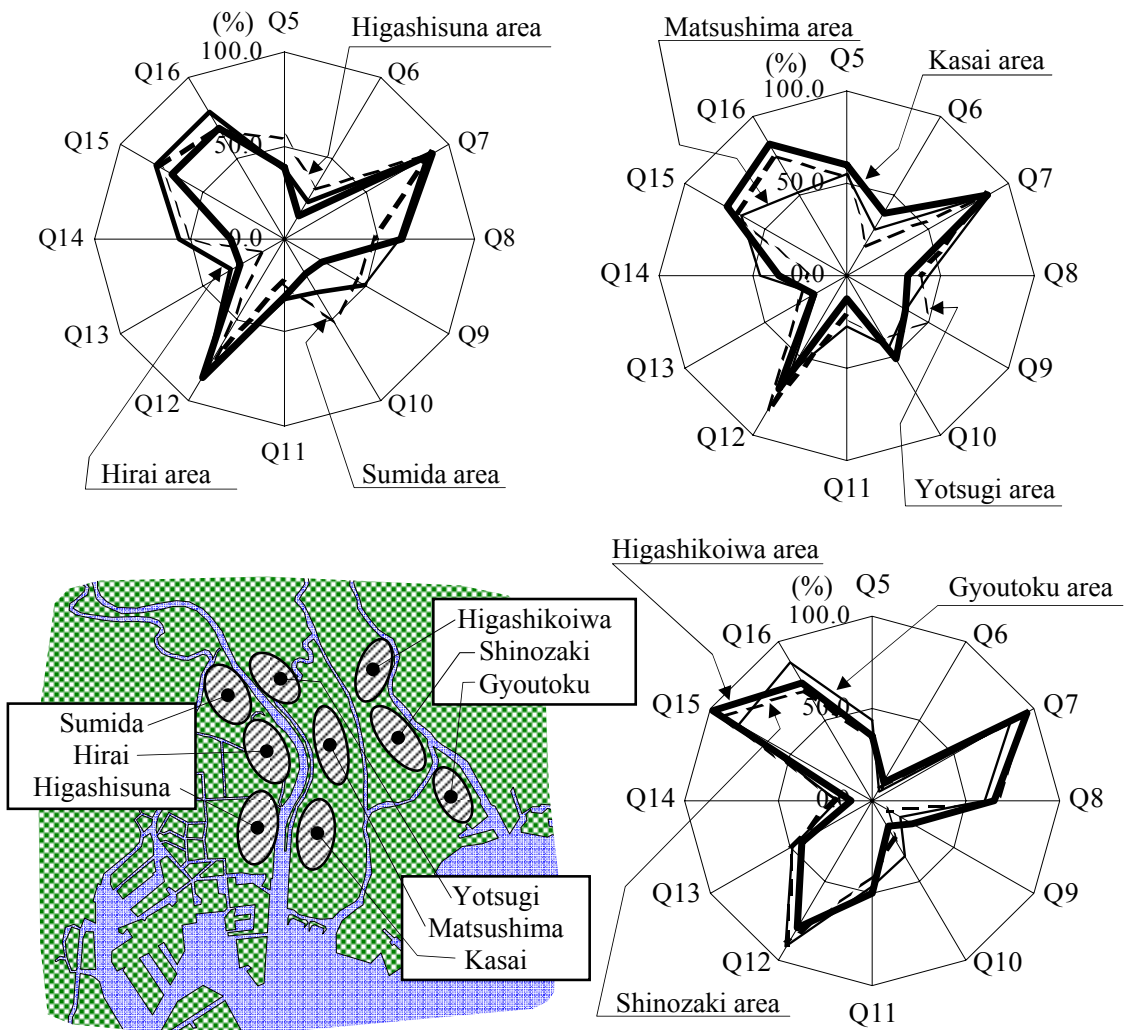

Figure 7: Survey results.

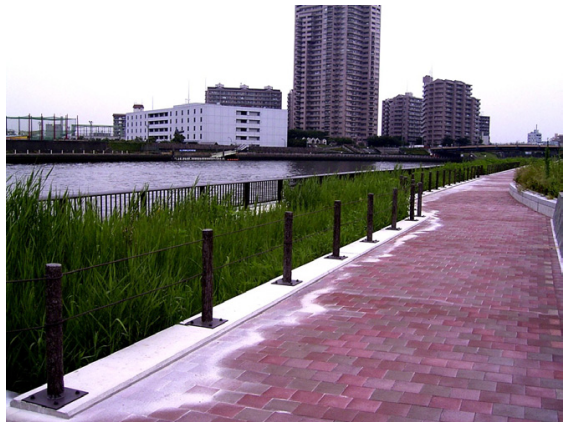

(a) Esplanade along river (Sumida River)

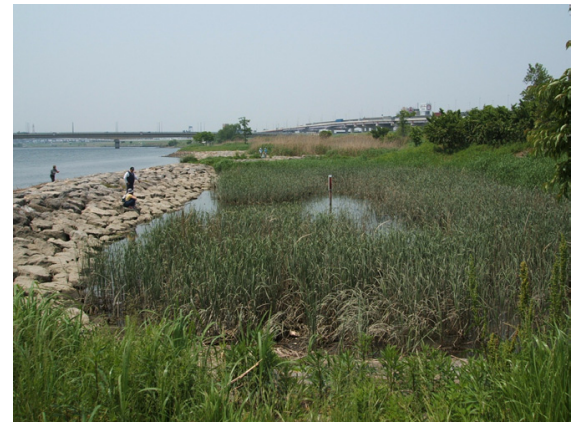

(b) Artificial wetland (Ara River drainage canal)

Figure 8: Examples of efforts on improvement of river environment. 


\subsection{Short-range goals}

Short-range river improvement goals of the Tokyo metropolitan government include the forestation of available riverfront open spaces. The government is also planning to improve water quality through the construction of fountains along the river for aeration and through an upgrade of the sewage system. Also, in order that the people have an affinity for rivers, the river managers of government have urged a construction of esplanade along the rivers as shown in Figure 8(a). Moreover, projects for dredging the polluted mud in the riverbeds and creating reed fields, as shown in Figure 8(b), have begun. Efforts to improve water quality have also included the education of upstream residents to increase the understanding of their impacts on downstream water quality.

Plans have been made for parks unifying the riverfront and designated meeting spaces around bridges. Currently, esplanades are being constructed along rivers, with access to the esplanades designed from bridges. Moreover, temporary boat-mooring facilities are being constructed to accommodate unlawfully moored boats and to improve the landscape of the river. Small ports in the river are being constructed for boat transportation and disaster response.

In addition, boat races and festivals along the river have been held in cooperation with local residents.

\subsection{Medium and long range goals}

Over time, the short-range goals will be completed. Moreover, as the bridges are reconstructed, site characteristics will be considered in the bridge design. In addition, pedestrian bridges will be built to increase interaction among neighbors. In the future, improved river water quality will allow children to play and swim in the rivers.

\section{Concluding remarks}

The present study evaluated flood damage in the Tokyo lowlands to identify methods to rehabilitate flood-damaged areas. We conducted an attitude survey of residents living in the Tokyo lowlands to determine the reasons for differing attitudes between residents of the Ara River basin and those living in along the Edo River. The survey clarified that the residents living along the Edo River have historically suffered only slight damage from floods, while residents living along the Ara River have sustained more significant losses.

The formation of sustainable river environments and the construction of flood protection structures are necessary for future improvements. Therefore, flourishing and safe riverfront properties must be supported through the maintenance and repair of dikes, seawalls, gates, and other flood protection structures in the Tokyo lowlands. Moreover, residents living along rivers must be educated about potential of impacts from flooding. 


\section{References}

[1] River Division, Bureau of Construction, Tokyo Metropolitan Government, Outline of Tokyo lowland rivers in 2008, 2008.

[2] Ministry of Land, Infrastructure and Transport, Tone-karyu river office, http://www.tonejo.go.jp/.

[3] Japan Metrological Agency, http://www.jma.go.jp/jma/index.html

[4] Gotoh, H. et al., Attitudes of Residents in the Tokyo Bay area toward flood hazards, Proceedings of River Basin Management IV, pp.117-126, WIT Press, 2007.

[5] Committee for the reconstruction of rivers flowing through historic Tokyo, Party Reviewing Tokyo Rivers, Party verdict on the improvement of the river environment in the Tokyo lowlands, 1999.

[6] Koutou, Flood Control Office, Bureau of Construction, Tokyo Metropolitan Government River Construction Plan, 2005. 